\title{
PRESENÇA DE COUTURE
}

\author{
GALENO LACERDA \\ Catedrático de Direito Judiciário Civil.
}

Encimada por um rosto de menina, transfigurado de angústia, lia-se esta passagem de Juan Zorrilla de San Martin:

"La injusticia es la madre del odio; el odio engendra la guerra; la guerra es una esfinge que mira con ojos inmóviles de hermosura siniestra; su beso es mortal y su hija suele llamarse Gloria".

Ao contrário daquelas meńsagens de ano novo, pequenas joias de arte e de esperança, com que Couture brindava os amigos, a dêste ano amanheceu singularmente trágica e pressaga. Lembro-me de que a contemplei com surpresa e desconfôrto. A tortura da inocência, o sinistro da glória e, por fim, o anelo: "Por un año de paz, de armas y de almas, van aqui los mejores votos".

Em 55 nos almejara êle: "Que o ano novo traga consigo a felicidade esperada; e, se não a trouxer, não nos roube a felicidade de continuar esperando"...

O trágico contraste de 56 , por desventura, não foi obra do acaso. A êle se ajusta um pensamento de Vaz Ferreira, mais de uma vez repetido por Couture:

"Son páginas de premuerte: hay una ciencia, un arte, un pensamiento que adquieren un acento muy particular cuando se tiene la vida un poco llena de muerte. No se trata, propiamente, de la obra póstuma; es algo más dramático y profundo. Es un estado inconsciente de creación que constituye algo así como la despedida de la vida. Quien haya escuchado mucho los últimos cuartetos de Beethoven, el Doppengänger de Schubert o el quinteto opus 44 de Schumann podrá entender esto plenamente" (1).

*Oracão proferida em sessão solene da Congregação da Faculdade de Direito de Pôrto Alegre, realizada em 12 de junho de 1956, em homenagem à memória 
A mensagem de 56 foi, com efeito, um pequeno lavor de pré-morte.

Faz um mês faleceu Eduardo Couture, o processualista mais eminente da América. Desapareceu aos 53 anos, na exuberância da vida e no esplendor da inteligência. Encheu-se de luto o Uruguai. A dôr aflorou aos corações de quantos, em três continentes, se situaram em sua trajetória de ciência e de beleza.

A Faculdade de Direito de Pôrto Alegre não poderia omitir as mais fundas manifestações de pesar pela perda irreparável; não poderia deixar de tributar homenagens póstumas as mais expressivas àquêle que tantas vezes iluminou nossas cátedras, expargindo entre nós a sedução de seu espírito.

Iniciamos o dia com o ato religioso e íntimo do Sacrifício da Missa, na intenção de sua alma, "da paz da alma", como almejavam os votos.

Reunimo-nos, agora, em ato oficial, em sessão solene de Congregacão, para testemunhar de público os sentimentos de luto desta Faculdade.

Por deferência especial de meus nobres pares, confiaram êles ao mais moço as palavras da tristeza. Não vai nisto distincão ao orador. O gesto é mais um requinte na homenagem ao grande morto. Exatamente há um ano, Couture, neste mesma sala aprovando-me em concurso para a cátedra de Direito Judiciário Civil, compartilhava, em certo sentido, as minhas responsabilidades com o magistério. Elegendo-me intérprete, escolheu a Congregação aquêle de seus membros que, sendo o mais modesto, era o único, contudo, a ostentar essa afinidade moral com o Mestre.

Dentre as Faculdades de Direito do Brasil, a mais vêzes honrada com a freqüência de Couture foi a nossa. Conferencista inigualável, a êle devemos os melhores instantes de beleza desta Casa. Sofremos também o fenômeno das demais Universidades do mundo: o da angústia das salas para o seu auditório. Com êle abrimos o mais honroso precedente no ensino superior do Brasil: o convite a um grande mestre internacional para integrar uma banca de concurso. Com êle vivemos horas inesquecíveis poucos dias antes de sua morte. Pôrto Alegre foi o último pedaco de terra estrangeira a agasalhar o infatigável andarilho do direito. De nós se despedira, no aeroporto, com a juventude de sempre, para, no dia seguinte, sucumbir ante a moléstia que o levaria ao túmulo.

Perda irreparável a do Uruguai. Lacuna insubstituível entre os mestres da processualística na América.
Em 1927, Eduardo Couture graduava-se advogado pela $\mathrm{Fa}$ culdade de Direito de Montevidéu.

A poetisa Ofélia Machado, colega de turma, assim depõe sôbre o estudante:

"Couture já se distinguia, como estudante, especialmente, por duas virtudes essenciais: sua solícita e profunda atenção por todos e cada um dos companheiros, atenção sincera, forte e delicada, desde as raízes da alma, e, de outra parte, sua avidez espiritual sempre desperta e curiosa ante tôdas as expressões da cultura, desejosa de formar e nutrir cada vez mais a personalidade séria, simples, nobre e afável. Talvez, dentre os colegas, outros se the assemelhassem, mas ninguém, como êle, mais afastado daquela unilateralidade sêca a que o estudo exclusivo do direito pode conduzir; nem mais ansioso por conservar a flexibilidade espiritual, nem mais respeitoso e tolerante para com as pessoas e os caracteres diversos; ninguém mais amante da arte e da música, nem mais dinâmicamente sensivel e fiel a um certo matiz sentimental" (2)

No ano seguinte, em 1928, com 25 anos de idade, iniciou a carreira no magistério, como aspirante a professor adjunto. Em 1931 , escrevia a tese sôbre $E l$ divorcio por voluntad de la mujer, e, com ela, conquistava o cargo de professor adjunto de Direito Processual Civil, obtido por concurso de forma tão auspiciosa, que n Conselho Diretor da Faculdade de Montevidéu, em ata de 16 de junho de 1931, "dejó constancia de que se estaba en presencia de un futuro profesor de gran valia" (3) E adianta Diaz de Guijarro: "O brevíssimo tempo transcorrido confirmou a predição: em 1933 foi nomeado titular da cátedra" (4).

Daí por diante, sua obra científica cada vez mais cresce em quantidade e qualidade.

Em 1932, publicava a Teoria de las diligencias para mejor proveer. No ano seguinte, La acción declarativa de la prescripción.

Em 1934 surge aquela que, depois, seria uma constante em sua obra, a preocupação ética do processualista: $O$ princípio de liberdade no sistema do processo civil.

Em 1936, publica o Curso sôbre o Código de Organização dos Tribunais. Em 38, El deber de decir la verdad en juicio civil, e, nêste mesmo ano, profere, na Faculdade de Direito de Buenos Aires, formosa conferência, de larga divulgação entre nós, sôbre a Oralidade e regra moral no processo civil.

(2) - Rev. de Derecho Procesal, 1946, 2a parte, págs. 81 e 82 Proceso Civil, ed. Antología Jurídica, Buenos Aires. 
Em 39, lança o Curso sôbre a Lei de Abreviação dos Juizos, preleciona admiràvelmente em Córdoba, em três conferências, sôbre a Trajetória e destino do direito processual civil hispano-americano, e, no Centro de Estudos Jurídicos de La Plata, disserta sôbre tema do qual sairia a monografia $A$ ação revogatória da coisa julgada fraudulenta.

Daí até 42 , prepara a primeira grande síntese teórica, sua obra predileta: Fundamentos del Derecho Procesal Civil, que analisaremos adiante.

Neste mesmo ano, profere, sob os auspícios da "Sociedade Amigos da Inglaterra", uma série de agudas conferências sôbre A justiça inglesa.

Em 1943, num curso ministrado na Universidade de Cuyo, abordou a tese das Garantias constitucionais do processo civil, qual haveria de caracterizar mais tarde sua obra científica, e onde, pela primeira vez, desenvolve o tema da ação como direito de petição. Daí por diante, seria êste o assunto predileto de seu labor jurídico.

Em 1944, volta ao tema perante as Universidades americanas, e profere substanciosa conferência intitulada Meio século de direito, em homenagem ao cinquentenário da "Revista de Derecho, Jurisprudencia y Administración", de que era diretor.

Ainda no mesmo ano, na $1^{\text {a }}$ Convenção Nacional de Advcgados do Uruguai, foi relator da tese De la Organización Judicial $y$ del Régimen Procesal, publicada depois em valiosa monografia.

De 43 a 45 , por unânime deferência de seus concidadãos, elaborou o admirável Proyecto de Codigo de Procedimiento Civil, em razão do qual recebeu, na terra natal, dos colegas, da Faculdade e dos alunos, a maior consagracão que pode exornar a vida de um jurista. Agradecendo-a, Couture começou com estas palavras: "Si algún dia en mi adolescencia, un personaje de la fábula, de esos que ponen el ensueño en los cuentos de los hermanos Grimm, me hubiera dicho: "pide lo que quieras", yo hubiera escogido algo muy semejante a este acto" (5).

Já tendo brilhado nas cátedras de São Paulo, publica em 1946, no Brasil, em língua portuguêsa, aquela que considerava a $2^{a}$ edição dos Fundamentos, bastante modificada em relação à anterior, integrada agora da teoria da ação como direito de petição. Ainda em 1946, viaja a Cuba, onde disserta sôbre a Revogação dos atos processuais fraudulentos.

No princípio de 47 , tem oportunidade de brindar o culto público mexicano com os primores de seu talento, em um curso de oito conferências sôbre a Teoria da boa fé no processo civil e a Interpretação e integração das leis processuais. Afirma o Prof. Niceto Alcalá-Zamora que, dos cursos de inverno da Escola Nacional do México, "la nota destacada la constituyeron los dos ciclos desenvueltos por el profesor Couture. A lo largo de sus ocho conferencias el aula "Jacinto Pallares", la de mayor cabida de la Escuela, se vió constante y literalmente llena, más exactamente, abarrotada" (6). Terminados os cursos, seguiu-se um debate entre o conferencista e onze mestres da Faculdade Mexicana, entre os quais Alcalà-Zamora, Garcia Maynes, Rafael de Pina e Recaséns Siches, sôbre os princípios de processo consignados nos nove primeiros artigos do Projeto Couture, debate que, pelo alto quilate mental dos participantes, constitui uma das mais brilhantes e agudas páginas do direito processual moderno.

Recebeu Couture, na ocasião, as honras de "Professor extraordinário", renovadas no Perú, quando, de passagem, prelecionou na Fačlldade de San Marcos.

De chegada a Montevidéu, publica, a nosso juízo, sua monografia mais perfeita: $O$ Conceito de Fé Pública - Introdução ao Estudo do Direito Notarial.

Neste mesmo ano de 1947, visita-nos pela vez primeira, pronunciando, nesta Faculdade, três conferências, verdadeiras joias de argúcia e elegância.

De volta ao Uruguai, lança alentada monografia em que estuda os aspectos processuais da Lei 10.783, sôbre direitos da mulher.

Em 48, publica o primeiro volume de seus Estudos, sob o título de A Constituição e o processo civil, onde enfeixa alguns trabalhos e monografias já referidos, e outros novos, os principais, dentre os quais destacamos a Tutela constitucional da justiça e Algumas nocões fundamentais de direito processual do trabalho.

Em 49, aparece o segundo volume dos Estudos, dedicado a Provas em matéria civil, condensação de vasta produção anterior sôbre o assunto.

A primavera dêsse ano haveria de reservar-lhe, porém, a glória, a apoteose na Sorbonne. A ela se refere Santiago Sentís Melendo, nestes têrmos: "No han sido los franceses quienes más empeño han puesto en conocer las corrientes del pensamiento procesal moderno. Sus maestros más destacados han prescindido casi en absoluto de la ciencia alemana y de la italiana. Era la voz de un hombre de América la que les llevaba el mensaje de lo que ocurre a las puertas de su propia casa. ... El triunfo académico fué rotundo. La nueva escuela procesal tuvo su cá-

(6) - Rev. de Derecho Procesal, 1947, 2a parte, pág. 63 
tedra en la Sorbona" (7). Suas quatro conferências se enfeixaram no volume intitulado Introdução ao Estudo do Processo Civil, publicado em várias línguas e enriquecido dos debates entre o professor de Montevidéu e os colegas de França. Por essas conferências, galardoou-o o Governo Francês com a comenda da Legião de Honra (8).

Depois da França, a Itália. E Couture subiu à cátedra da Universidade de Roma, onde prelecionou diante de Carnelutti, Betti, Del Vecchio, Maroi, Ravà, De Francisci.

Ainda em 1949, nos deslumbra com filigrana de requintado lavor, Os mandamento do advogado, na frase de Amílcar Mercader, "mensagem de evangélica ressonância, cinzelada com perícia de miniaturista" (9).

Em 1950, engasta nos escritos em honra de Carnelutti uma pérola intitulada Carnelutti y nosotros. - Un capítulo de la sociologia de la cultura.

Enriquece, em 1951, os "Estudos em honra de Redenti" com um trabalho de alto valor: $O$ processo como instituição, no qual dá o último toque à sua teoria do processo, consignando-a, com êsse novo feitio, na $3^{\text {a }}$ edição dos Fundamentos, que aparecem, no mesmo ano, inteiramente refundidos.

Ainda em 1951, sai do prelo o terceiro volume dos Estudos, dedicados agora ao juíz, às partes e ao processo: trabalhos novos, remeditados ou republicados.

Embora continuasse a frequentar os principais Congressos Jurídicos Internacionais e a lecionar em Faculdades estrangeiras, sua produção jurídica externa decresce a partir de 1950 . ' $\mathrm{E}^{\prime}$ que desde então passara a dedicar todo o esfôrço de seu talento àquela que será a grande obra póstuma - o "Vocabulário de Direito Processual Civil".

Em 1953, sai à luz um mimo literário - La Comarca y el Mundo - onde sua alma de artista se revela em plenitude.

A última cátedra a que assomou foi brasileira, a da Faculdade de Direito de Curitiba, onde ministrou uma série de aplaudidíssimas aulas sôbre os conceitos fundamentais do direito.

Seu derradeiro trabalho publicado é recente, e surgiu também no Brasil: Interpretação das Leis Processuais, bem cuidada tradução da Prof. Gilda Corrêa Meyer Russomano, da Faculdade de Direito de Pelotas. Nêle se incluem as conferências proferidas e o debate travado no México, e dois trabalhos novos: um, que pode ser considerado o prólogo do Vocabulário, e outro, em forma esquemática, sôbre Interpretação das leis processuais, sem dúvida,

(7) - Rev. de Derecho Procesal, 1950, 2a parte, págs. 99 e 103.

(9) 二 Rev. de Derecho Procesal, 1949, $2^{\text {a }}$ parte, págs. 152 e 154. o mais alto momento de penetração filosófica de Eduardo Couture, revelador de profundo amadurecimento de espírito, e prenunciador de obra porvindoura, o seu grande Tratado, que ficou em esperança...

Qual o valor dessa imensa atividade científica, dessa inquieta e febril produção?

Não é tarefa fácil esboçar-lhe, neste momento, uma visão de perspectiva.

Que se tratava de um mestre de vanguarda do direito processual, não resta a menor dúvida. Bastem-nos as referências de Calamandrei e do sóbrio Carnelutti, que o destacam entre os mais eminentes processualistas estrangeiros (10).

A êle se deve a plena introducão na América Latina, não só do conhecimento da processualística alemã e italiana, como, principalmente, graças à sua atração pessoal, a êle devemos o gôsto e a emulação pelo estudo de um ramo do direito até então desprezado e árido.

Não foi, porém, Couture mero repetidor. Tem a seu crédito, na doutrina do processo civil, uma contribuição pessoal inestimável: a integração constitucional da disciplina, a visão política de seus institutos fundamentais, num ensaio de superação e de unidade do direito. Esse, o traço geral de sua obra. Mas nela há outros filóes de grande riqueza.

Num esfôrço de síntese da produção de Couture, eu a dividiria em quatro obras fundamentais, correspondentes a três momentos diversos de seu espírito criador: os Estudos, os Fundamentos, o Projeto e o Vocabulário.

De nada valeria, porém, a tentativa de interpretação de cada um dos monumentos, se não procurássemos conhecer, antes, o homem que os talhou.

Creio que todos concordarão em que, como a ninguém, calha a Couture o conceito de "esteta do direito".

O tema das relações da arte com o direito tem tido instantes de fecunda beleza na literatura jurídica de todos os tempos, a partir do velho conceito romano - jus est ars boni et aequi até aos nossos dias, através, dentre outras, das obras de Dernburg e Vico e, mais recentemente, de Carnelutti, Biondi e Maggiore.

Em pequeno trabalho de alto esmêro, Estetica del diritto, sintetiza Maggiore a correlação entre os dois domínios da ação humana, desta forma:

(10) - Riv. di Dir. Proc. Civile, 1939, 1" parte, pág. 69, e Riv. di Dir. Proc., 
"Justiça significa ordem, e ordem é beleza. O justo é, pois, um predicado ético e também estético" (11).

Em tôda autêntica criação do direito, legislativa, interpretativa ou doutrinária, há, com efeito, a preocupação por uma fórmula ideal de justiça, a ânsia de descobrir a norma adequada à conduta humana. E, nesses altos momentos de inspiração, a angústia do jurista é uma angústia de artista.

De tôdas as disciplinas jurídicas, a que mais se presta à insatisfação da arte é justamente a do processo. Não é êle, acaso, o instrumento de realização do direito e da justiça? Como a palavra é o instrumento do poeta, a pedra o do escultor, as notas o do músico, assim também o processo deveria ser o da justiça.

Se o poeta luta com a rusticidade da palavra, se o escultor sucumbe ante a impassividade da pedra, se o músico não alcança a harmonia sonhada, também o processualista sofre com a imperfeição do instrumento, no anelo incontido de justiça.

O caráter instrumental do processo deve ter atraído, sem dúvida, a vocação artística e o maravilhoso humanismo de Couture.

A nota de harmonia e de integração vamos encontrar em tôda a sua obra, nos vários estágios de criação.

O labor do jurista passa, em regra, por quatro momentos criadores diversos: análise inicial, síntese dos conceitos fundamentais, análise crítica posterior e síntese final.

Em Couture, encontramos os três primeiros momentos. O último a morte o impediu de realizar.

Os primeiros ensaios, até surgirem os Fundamentos, integram a análise inicial. Nêle deparamos, como preocupação fundamental, com o problema moral no processo civil, preocupação que jamais o abandonaria, e que revela a ânsia de afinar o instrumento, para imunizá-lo das perversões da injustiç. "Estos grados de la responsabilidad, que comienzan con la simple condena al pago de los gastos del juicio y culminan con el delito de "fraude procesal" - dirá êle mais tarde - reclaman el ajuste de nuestros Codigos a las orientaciones más recientes relativas a la vigencia de la regla moral en el proceso civil". (12).

Os Fundamentos pertencem ao segundo momento, o da primeira síntese. As três elaborações sucessivas da obra, e uma quarta, que estava em andamento, em língua francesa, demonstram a inquietação do artista pela perfeição.

Carnelutti, com a severidade habitual de sua crítica, adjetiva os Fundamentos como obra "mais elegante do que robusta" (13).

(11) - In Scritti Giuridici in onore di F. Carnelutti, vol. I, pág. 284

(12) 三 Estudos, I, pág. 45.
O mestre italiano, na verdade, não lhe compreendeu o sentido e o valor.

Do esteta do direito não se podem reclamar as altas vertigens do pensamento, nem o particularismo de análises que arrisquem deformar o todo. Harmonia de linhas, tentativas de conciliacão, visões integradoras - estas, sim, serão sưs preocupações fundamentais.

Ora, nos Fundamentos encontramos estas constantes. Seu objetivo primeiro é a inserção do direito processual na Constituição. Se as teorias da ação como direito de petição, e da exceção como garantia de processo legal, não correspondem a altas abstraç̃os são, contudo, integradoras do direito em plenitude.

Nelas surpreendemos a influência de Kelsen e de seu discípulo Carlos Cossio sôbre o pensamento de Couture. O que, porém, impressiona o processualista uruguaio na obra dêsses juristas filósofos é, ainda, um dado estético, e não pròpriamente a axiologia da construção filosófica. Esta, êle não a discute, nem dela cogita.

$\mathrm{O}$ que em Kelsen deslumbra a Couture, tanto que o elegeu como o jurista mais representativo do último meio século, é, conforme haveria de confessar, a sua "pureza metódica" (14), harmonia da gradação da ordem jurídica, levada por Cossio até aos extremos da elaboração processual.

A forma é que o seduz. Não o conteúdo. Que afinidade, com efeito, poderia haver entre a redução kelseniana do direito a mera hipótese gnoseológica e as contínuas afirmações de princípios jurídicos e morais, densos de conteúdo, com que se topa a cada passo na obra de Couture?

Até mesmo a sua gnoseologia jurídica afasta quaisquer implicações com o relativismo kantiano. Ouçamo-lo nêste tópico: "Las reglas de la sana crítica son reglas del correcto entendimiento humano; contingentes y variables con relación a la experiencia del tiempo y del lugar; pero estables y permanentes en cuanto a los principios lógicos en que deve apoyarse la sentencia" (15).

A teoria política do processo, sua inserção, até à minúcia, no direito constitucional, representa, pois, adesão estética ao método de Kelsen, e construção de altíssimo valor para uma visão de conjunto e integradora do direito processual no todo do direito.

Couture se desvela no acabamento do livro, os Fundamentos, nêsse esfôrço panorâmico de síntese inicial. Confessa, em certo momento, como o artista, que a teoria construída representa algo "como o fim de uma jornada" (16).

Faltava-lhe, entretanto, para a perfeita harmonia da constru- 


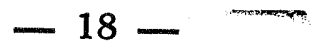

ção, a visão teleológica do processo. Carecia inundá-lo da idéia de fim. $E$ isto êle o faz, aderindo à teoria da instituição, desenvolvida no belíssimo ensaio dedicado a Redenti. Trata-se de adesão construtiva, em que a idéia de instituição, expurgada de habituais imprecisões, perfeitamente caracterizada e circunscrita, é aplicada ao processo, emprestando-lhe, assim, um sentido orgânico e finalista.

Tudo isto se contém numa ou noutra edição dos "Fundamentos". E' na verdade um livro elegante, mas também, sem dúvida, robusto, porque preencheu uma lacuna na ciência processual.

O terceiro momento, na obra de Couture, é representado pela análise crítica, correspondente à maturidade do Mestre. Os trabalhos já referidos, sôbre a instituição e o sentido político do processo e, principalmente, o Projeto e o Vocabulário são as grandes expressões desta fase.

O Projeto satisfaz ao ideal estético do jurista: poder sonhar com um instrumento perfeito de realização da justiça. Couture mesmo confessa que "não há Exposição de motivos que não seja um texto de ilusão, superando o regímen anterior" (17)

No Projeto verteu êle todo o idealismo, e logrou fazer obra de alta qualidade técnica, sob o lema: simplicidade, probidade e eficácia.

Ainda não surgiu estudo à altura dêsse Projeto. $O$ que se poderá dizer, contudo, é que se trata de obra de inspiração obrigatória para qualquer codificador futuro.

E, por fim, chegamos ao Vocabulário, sua obra póstuma. Dela só vimos as provas de imprensa, que o trabalhador infatigável trazia consigo na última viagem. Não parecerá estranho que alguém, no apogeu da criação científica, se detenha em trabalho dessa ordem, talvez mais próprio do desencanto da velhice? Em Couture, porém, deveria ser êsse o caminho.

A minúcia do esteta, o cuidado do detalhe impunham-lhe tal esfôrço, antes de lançar-se à aventura da síntese final. Êle próprio o diz: "Uma tarefa da natureza daquela que ficou esboçada é um esfôrço para superar a nossa habitual imprecisão... . E' uma tarefa obscura, mas necessária... Se tudo isso for alcançado, se se puder levar a bom têrmo êsse anelo de precisão, de clareza e de rigor no uso de nosso instrumental de trabalho; se, mediante um esfôrço coletivo da índole daquêle que mencionamos, lograrmos fazer passar nossas principais palavras pelo crivo de uma crítica adequada - teremos dado um passo adiante no caminho da ciência a que acabamos de nos referir" (18).
$\mathrm{O}$ artista cuidara seis anos de afinar o instrumento para a síntese final.

O Tratado ficou em esbôço, como semente escondida, de alto teor germinativo, enclausurada na recentíssima edicão brasileira de sua Interpretação das Leis Processuais.

A sinfonia do jurista permaneceu inacabada...

Sua vida, "uma entrega perfeita ao ideal", como dissera certa vez referindo-se a Bentham, deveria conhecer, agora, o verdadeiro amor e a beleza incriada.

$O$ humanista profundo escrevera um dia:

". . . las formas de la justicia son tan solo la corteza del derecho. Rota esa corteza, hallamos solamente hombres, cosas y profundos anhelos de vida. La justicia no es sólo un continente; por su interior corre la vida humana, entrañable y dramática, como que en ella se va decidiendo a cada instante el destino mismo del hombre" (19).

Chegara para êle a hora de conhecer a fonte da justiça, da vida e do destino.

Quem escrevera um dia: "Nunca saberemos na vida em que medida a conquista é um fim ou um novo comêço, e por que profuñủas razões não há outra chegada que aquela que deixa bertos indefinidamente diante de nós os caminhos do bem e da virtude" (20), haveria de conhecer, agora, a fonte de todo 0 bem e de tôda a virtude.

O beijo do amor divino lhe forra transmitido por seu amigo Carnelutti. $\mathrm{Na}$ "Comarca e o Mundo" jaz engastada essa pequena joia mística:

Conta-nos êle que, em momento de grande emoção, Carnelutti lhe confiara: "A vida, meu querido amigo, é como uma destas árvores que nos rodeiam; na juventude gozamos o espetáculo, a beleza da folhagem, os cantos que a povoam; mas é preciso atingir à velhice, como eu, para ver os galhos desnudos do inverno e chegar, por fim, a compreender que as fôlhas da primavera não nos deixam ver o céu...

E Couture adianta: "Esta confissão se cravou como uma flecha. As palavras pareciam ditas para se perderem na tarde. Mas não foi assim..." (21)

A flecha do amor de Deus o atingiu.

(19) - Fstudos T 156

(20) - Los mandamientos del abogado, 3a ed., pág. 61 
A notícia da consumação, trouxe-a, há trinta dias, um recorte de jornal de Montevidéu (22):

"Desta maneira foi sepultado êste homem, de tão relevante prestígio dentro e fora de nosso país, o qual, em seu último mo mento, deu-nos também a outra lição, a da religiosidade, pois que, na lucidez de seus sentidos, recebeu os últimos Sacramentos e os auxílios espirituais de nossa religião".

\section{O CENTENÁRIO DE UMA GRANDE VIDA}

\section{JOSE' SALGADO MARTINS}

Catedrático de Direito Penal

O Rio Grande do Sul comemorou, a 29 de julho de 1957, o centenário do nascimento de Joaquim Francisco de Assis Brasil.

Síntese, no mais alto grau, das melhores virtudes da gente riograndense, Assis Brasil foi o exemplar perfeito do homem de pensamento e do homem de ação.

Escritor, orador, parlamentar, diplomata, político na acepção mais alta e nobre da palavra, o preclaro cidadão riograndense imprimia a tôdas as manifestações do pensamento e a todos os atos em que se concretizava a sua conduta pública e privada, o signo, a altitude e o fulgor de uma personalidade de exceção.

Desde muito jovem, ainda nos bancos acadêmicos, na tradicional Faculdade de Direito de São Paulo, revela os grandes predicados com que a Providência o dotou para desempenhar 0 eminente papel a que estava destinado.

Na predicação da República, forjou e aprimorou o seu talento de escritor, orador e pensador político, um dos mais insignes, de sóbria elegância, preciso, brilhante e vigoroso na exposição, na crítica e no debate. Historiador, escreveu lúcido ensaio sôbre as causas da República riograndense de 1835 , que é, ao mesmo tempo, um ensaio sociológico e político sôbre uma das fases mais expressivas da sociogênese do Rio Grande do Sul. Pensador, dentre vários e brilhantes trabalhos de conteúdo jurídico e político, escreveu "Do Governo Presidencial na República Brasileira" e "Democracia Representativa". Orador soberbo, ao modêlo ciceroneano e demostênico casava harmoniosamente o sentido moderno da oratória política, de feição mais britânica que gauleza, sem perder os primores da elegância e do brilho no conceber e no dizer, ao lado do timbre de graça, bom gôsto e imaginacão. O discurso que proferiu em 1908, na fundacão do Partido Republicano Democrático, representa um dos mais notáveis diplomas da eloquência política em língua portuguêsa, ao qual não falta, sequer, a fidelidade ao modêlo clássico: o exórdio ou preâmbulo 